\title{
DOCUMENTOS
}

\author{
Carmen Caamaño
}

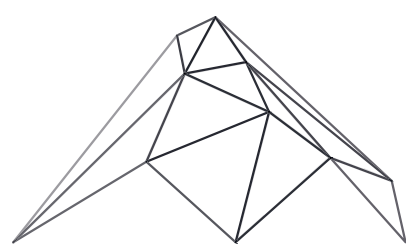





\section{DISCURSO DE INAUGURACIÓN DEL NUEVO EDIFICIO DEL INSTITUTO DE INVESTIGACIONES SOCIALES DE LA UNIVERSIDAD DE COSTA RICA}

Carmen Caamaño Morúa

Señor Dr. Henning Jensen, rector de la Universidad de Costa Rica

Señora Dra. Rita Meoño, miembro del Consejo Universitario

Señor M.Sc. Francisco Enríquez, decano de la Facultad de Ciencias Sociales Señores y señoras autoridades universitarias, decanos, directores de unidades académicas, centros, institutos y estaciones experimentales Señores y señoras exdirectores del Instituto de Investigaciones Sociales Compañeras y compañeros de la Oficina de Seguridad y Tránsito

$y$ de la Oficina de Mantenimiento Compañeras y compañeros del Instituto de Investigaciones Sociales

Docentes y estudiantes Amigos y amigas

Es un honor y una gran alegría para mí estar hoy en el acto de inauguración del nuevo edificio del Instituto de Investigaciones Sociales, actividad que coincide con la celebración, este año, de nuestro cuadragésimo aniversario.

Lo que hoy celebramos es producto de un esfuerzo sostenido de diferentes generaciones de universitarias y universitarios, iniciando por el trabajo que llevó a cabo el Dr. Daniel Camacho, para fundar el Instituto de Investigaciones Sociales en el año 1975. Posteriormente le correspondió al Dr. Jorge Rovira Mas, director durante el periodo 19831987, luchar por el espacio que hoy ocupamos. El Dr. Jorge Rovira, junto con el personal de entonces protagonizó una gran lucha, con toma de edificio incluida, como suele suceder, para que el antiguo edificio fuera asignado al Instituto de Investigaciones Sociales.

Más de diez años después de esto, la Dra. Ciska Raventós, directora durante el periodo 1999-2005, dio inicio a las gestiones para, en un principio, remodelar nuestro edificio y, luego, plantear la necesidad de uno nuevo. El director que le siguió, el Dr. Carlos Sandoval (periodo 2005-2009) continuó con las gestiones, logrando que 
se dibujaran los planos y se iniciaran los procesos administrativos necesarios para obtener el presupuesto para la construcción.

Cuando asumí la Dirección, en el año 2009, me correspondió la responsabilidad enorme de darle continuidad al proyecto en el cual todo el personal del Instituto tenía puestas sus esperanzas. Recuerdo que por un tiempo me aparecía en todas las inauguraciones de edificios que hacía doña Yamileth González, la rectora de entonces, y que en determinado momento enviamos también correos tanto a doña Yamileth como a don Héctor González, vicerrector de Administración, con fotos que mostraban al personal del Instituto limpiando los restos de barro que dejaban las inundaciones que sufría nuestro viejo y vulnerable edificio, como estrategias para poder avanzar con nuestro proyecto.

A doña Yamileth y a don Héctor les agradecemos habernos escuchado y haber dado inicio a los procesos necesarios para que pudiéramos concretar este proyecto y a don Henning Jensen el haberle dado continuidad para que hoy sea una realidad. Trece años han pasado desde las primeras gestiones $y$, finalmente, hoy podemos disfrutar de este maravilloso espacio.

Agradecemos el apoyo de una serie de unidades dentro de la Universidad: OPLAU, que nos incluyó en el presupuesto; OEPI, que con su excelente personal diseñó y se hizo cargo de la supervisión de la construcción: Silvia Rivera y Kevin Cotter fueron los arquitectos y Mauricio Piedra el ingeniero a cargo. Los trabajadores de la Empresa Constructora Roca, a cargo del ingeniero Marvin Rodríguez Esquivel, crearon un edificio funcional y hermoso con finos detalles y acabados.

Para que ellos pudieran hacer este edificio, el Instituto debió trasladarse a un espacio provisional, la antigua Casa Alforja, en donde permanecimos durante un poco más de un año. La Vicerrectoría de Administración y Fundevi nos apoyaron para que tuviéramos un espacio adecuado para continuar con nuestras funciones. Los compañeros del Centro de Informática hicieron las conexiones en ese momento para que pudiéramos trabajar en ese lugar, y volvieron a instalarlas en este nuevo edificio.

Por su parte, los compañeros de Mantenimiento al mando de don Óscar Molina y bajo la coordinación de don Fernando Fernández, desmontaron paredes del viejo edificio y las convirtieron en oficinas y una recepción en la casa donde nos alojábamos, y ahora nos han ayudado en miles de labores para instalarnos nuevamente aquí.

También, muy importantes, han sido los compañeros y las compañeras de Seguridad y Tránsito bajo la coordinación de don Gustavo Pérez, quienes nos brindaron protección durante el año que estuvimos fuera del campus.

El regreso no hubiera sido posible sin el apoyo para el pago de la mudanza por parte de la Vicerrectoría de Investigación y la Vicerrectoría de Administración, la cual ejecutó el personal de Mudanzas Mundiales a cargo de don Boris Quinde, y no tendríamos estantes en la biblioteca y sillas en la sala de audiovisuales sin el apoyo 
adicional de la Rectoría, coordinado por doña Gloria Meléndez. Tampoco contaríamos con un refrigerio sin el apoyo extra de la Vicerrectoría de Investigación.

Todo esta colaboración tan importante y que agradecemos mucho fue gestionada incansablemente por Kathia Castro, nuestra jefe administrativa. Además, a ella, al personal administrativo del Instituto, a las compañeras del Centro de Documentación, al personal de investigación y a muchos de las asistentes les debemos el trabajo arduo y extendido más allá de sus jornadas laborales, no solo para efectuar los traslados, limpiar los diferentes espacios, acomodar los libros en los estantes, y un sin fin de tareas que se hacen cuando uno ama un espacio, sino también para que las labores del Instituto no se vieran interrumpidas significativamente durante estos procesos.

Agradecemos al señor decano de la Facultad de Ciencias Sociales, M.Sc. Francisco Enríquez y a su personal la colaboración que nos dieron para que pudiéramos llevar a cabo los trámites necesarios sin mayores contratiempos.

Por todo esto, cuando miro este edificio me emociono profundamente, pues son muchas las personas que están detrás, que nos honran con su trabajo y que nos comprometen a mejorar cada día.

A estas personas es a quienes queremos honrar el día de hoy. Ellas y ellos me hacen recordar el poema de Bertold Brecht "Preguntas de un trabajador que lee", el cual dice:

¿Quién construyó Tebas con sus siete torres?

En los libros aparecen los nombres de reyes.

¿Arrastraron los reyes los trozos de piedra?

Y la Babilonia varias veces destruida, ¿quién la reconstruyó otras tantas?

¿En qué casas vivían los albañiles de Lima cuando deslumbraba con su oro?

¿Adónde fueron los peones la tarde en que terminaron la muralla china?

La gran Roma está llena de arcos de triunfo. ¿A quién vencieron los césares?

¿El muy nombrado Bizancio sólo tenía palacios para sus habitantes?

Incluso en la legendaria Atlántida, la noche en que el mar se la tragó, los que se estaban ahogando clamaban por sus esclavos.

El joven Alejandro Magno conquistó la India.

¿Él solo?

César venció a los galos.

¿No llevaba con él ni siquiera a un cocinero?

Felipe II de España lloró cuando se hundió su flota.

¿Nadie más lloró?

Federico II venció en la Guerra de los Siete Años.

¿Quién ganó además de él?

Cada página, una victoria. 
¿Quién cocinó el banquete para celebrarlas?

Cada diez años, un gran hombre.

¿Quién pagó los gastos?

Tantas crónicas.

Tantas preguntas.

Es la gente la que está detrás de los grandes edificios, y también de los pequeños. Pensando en la gente es que el Instituto de Investigaciones Sociales ha venido trabajando desde hace ya 40 años. Su legado nos obliga a responder críticamente a las demandas regionales, nacionales y universitarias de nuestro tiempo, desde una perspectiva de responsabilidad social y política. Para ello, desarrollamos procesos inclusivos de definición que partan del análisis sobre las condiciones actuales en la región, el país y la universidad y del papel responsable que debemos jugar en todos estos ámbitos a partir de la vinculación entre investigación, docencia y acción social.

Haciendo honor a la trayectoria que inauguró el Dr. Daniel Camacho en el año 1975, a la luz de los acuerdos del Tercer Congreso Universitario:

Seguimos luchando por un Instituto y una Universidad que desarrollen su tarea comprometida con la sociedad en un marco crítico del mercantilismo que invade nuestros tiempos. Por ello promovemos el diálogo entre diferentes unidades académicas y órganos de decisión universitaria en defensa de los valores académicos, sociales y políticos que buscan la inclusión, la igualdad y la autonomía, y en donde las Ciencias Sociales son fundamentales.

Buscamos generar procesos colectivos de construcción institucional amparados en la excelencia académica, la capacidad crítica y los más altos valores humanos.

Impulsamos la discusión sobre el vínculo Universidad-Sociedad desde una perspectiva de "diálogo de saberes" a través de diferentes proyectos de investigación, docencia y acción social, y para ello divulgamos nuestro quehacer tanto mediante publicaciones académicas, mesas redondas, talleres, atención al público en nuestro Centro de Documentación, así como a través de medios virtuales, por lo que cada vez se utiliza más el recurso de las redes sociales.

Seguimos intentando establecer redes académicas que lleven hacia investigaciones colaborativas, fortaleciendo especialmente el vínculo con Centroamérica, para generar unas Ciencias Sociales desde la región.

También nos hemos comprometido en el vínculo profundo con la Facultad de Ciencias Sociales y con otras unidades académicas de esta universidad y de otras universidades públicas para promover la discusión académica y el trabajo colaborativo. 
Creemos en el diálogo intergeneracional, y llevamos a cabo acciones concretas para que se dé el recambio generacional bajo condiciones óptimas de excelencia académica, responsabilidad institucional y justicia laboral frente a los problemas que genera el interinazgo en la UCR.

Luchamos porque unas Ciencias Sociales críticas saquen a la luz lo que se esconde, lo que es injusto y genera sufrimiento para las grandes mayorías, y buscamos proponer otras formas de hacer las cosas.

Desde los dos programas de investigación del Instituto tratamos de llevar a cabo esta labor. Estos son: Nuevas formas de acumulación, distribución y desigualdad, y Culturas, instituciones, subjetividades.

Los programas vienen a ser los espacios académicos colectivos desde donde se gestan preguntas que eventualmente se convierten en proyectos de investigación para un número que varía entre 20 y 26 investigadores e investigadoras, además de las y los asistentes, pasantes y becarios.

El Programa Culturas, Instituciones, Subjetividades tiene como objetivo general estudiar procesos de construcción de tejidos sociales, procesos de constitución de identidades y procesos de diferenciación social, tomando en cuenta categorías de clase, género, etnia y generación, entre otras. Así, incluye proyectos diferentes, con distintas perspectivas teóricas, metodológicas y disciplinarias, relacionados con la lucha por el espacio en las zonas urbanas, con el tema de la migración, con temas relativos a poblaciones indígenas y afro-costarricenses y con la construcción de institucionalidad.

El Programa Nuevas formas de acumulación, distribución y desigualdad tiene como objetivo principal estudiar las (nuevas) formas y procesos de acumulación, distribución y desigualdad en Costa Rica y la región centroamericana, así como las expresiones de lucha y conflicto producto de estas relaciones sociales desiguales. Entre sus proyectos encontramos algunos relacionados con el estudio de las políticas públicas, con el análisis de las élites en el poder, con los procesos de lucha por la tierra en zonas rurales, con movimientos sociales y acciones colectivas.

En este nuevo edificio los programas y los equipos de trabajo dentro de ellos tendrán espacios adecuados para reunirse y para presentar avances y resultados de investigación.

Los resultados de los proyectos de investigación y acción social del Instituto nutren nuestra práctica docente, se publican en libros o artículos académicos, y en materiales audiovisuales que permiten una mayor difusión y que se presentan en talleres, charlas, mesas redondas y otras actividades dirigidas a las poblaciones con las que se ha trabajado y a públicos más amplios.

Además, contamos con el Programa Nuevas Voces en Ciencias Sociales, que este año cumplirá su décimo año consecutivo. Este Programa reúne cada año a jóvenes 
de la Facultad de Ciencias Sociales y de otras Universidades para presentar sus Trabajos Finales de Graduación en el marco de la Semana U. Algunos de ellos son becarios o exbecarios del Instituto, pues con el apoyo de la Vicerrectoría de Investigación otorgamos cinco becas anuales de medio tiempo a estudiantes de grado y posgrado para que desarrollen sus tesis con nosotros. De hecho, el día de mañana estaremos anunciando quiénes ganaron la beca para el año 2015, la cual constituye la convocatoria número 18, pues este programa inició en 1997.

Por último, ponemos a disposición el Centro Integrado de Documentación Centroamericana en Ciencias Sociales (CIDCACS) con una colección especializada que crece día tras día y que ahora cuenta con instalaciones que permiten ofrecer una atención óptima a estudiantes, docentes y público en general, y el Anuario de Estudios Centroamericanos, el cual tiene sede en nuestro Instituto.

Para finalizar, deseo invitarles a que a lo largo del año nos acompañen en las diferentes actividades públicas que iremos anunciando y que se desarrollarán en el marco de nuestro 40 Aniversario, incluida la exposición de nuestros proyectos durante la EXPO UCR 2015.

Muchas gracias a todos y todas por formar parte de una $\mathrm{u}$ otra forma de este gran proyecto que es el Instituto de Investigaciones Sociales. 